\title{
PERFIL LABORAL POR COMPETENCIAS DEL PUESTO DE DIRECTOR DE CARRERA EN LA UNIVERSIDAD CATÓLICA DE COSTA RICA
}

\author{
COMPETENCY-BASED JOB \\ PROFILES FOR SCHOOL DEANS AT \\ UNIVERSIDAD CATÓLICA DE COSTA RICA
}

\section{JOSE FABIÁN ELIZONDO G. ${ }^{i}$}

KIMBERLY ROMÁN V:ii

Recibido: 14 de Julio de 2019

Aceptado: 1 de noviembre de 2019

\footnotetext{
' Universidad de Costa Rica, Facultad de Letras, San José, Costa Rica. (josefabian.elizondo@ucr.ac.cr)

ii Ministerio de Educación Pública, San José, Costa Rica. (kimrove@hotmail.com)
} 



\title{
PERFIL LABORAL POR COMPETENCIAS DEL PUESTO DE DIRECTOR DE CARRERA EN LA UNIVERSIDAD CATÓLICA DE COSTA RICA
}

\author{
COMPETENCY-BASED JOB \\ PROFILES FOR SCHOOL DEANS AT \\ UNIVERSIDAD CATÓLICA DE COSTA RICA
}

Jose Fabián Elizondo G., Kimberly Román V.

Palabras clave: perfil por competencias, administración educativa, director de carrera, manual de labores

Keywords: competency-based job profile, higher education, school deans, job description manual

\section{RESUMEN}

El objetivo de este trabajo es determinar el perfil laboral de los directores de carrera de la Universidad Católica de Costa Rica, localizada en San José, Costa Rica. Todos los participantes de este proyecto pertenecen a las diferentes direcciones académicas de dicha Institución. La muestra incluye nueve profesores que ejercen sus labores como directores de carrera o de escuela en sus áreas de especialidad, los cuales expresaron sus puntos de vista sobre la creación de un manual de labores específicas para cada dirección académica y su respectivo perfil laboral por competencias. Los datos se recolectaron por medio de una 
entrevista estructurada con los investigadores. Los datos arrojan la necesidad de elaborar un manual de labores específicas del director de carrera ya que, dada la falta de especificidad en las tareas realizadas por los directores, los procesos administrativos se ven entorpecidos y se redoblan los esfuerzos. Adicionalmente, los resultados demuestran que dicho manual podría promover una nueva y adecuada selección del personal basada en sus competencias laborales.

\section{ABSTRACT}

The objective of this research project is to determine the job profile of the different school deans of the majors offered at Universidad Católica de Costa Rica, located in San José, Costa Rica. All of the participants of this project belong to the different schools within this university. The sample includes nine instructors who work as school deans in their specialty areas, and who expressed their points of view regarding creating a specific job description manual for each school as well as a competency-based job profile. The data was collected through a structured interview with each school dean. The data shows that the elaboration of this specific job description manual is necessary since the tasks carried out by the school deans are sometimes done more than once or done ineffectively due to the lack of specificity in their current job descriptions. In the same fashion, the results provide some insight on how new and adequate competency-based recruitment procedures can be implemented.

\section{INTRODUCCIÓN}

El papel del administrador educativo en el mundo de la educación superior presenta retos que son capaces solamente de afrontar aquellos que se encuentren capacitados para tan específica función. En la Universidad Católica de Costa Rica, los directores de carrera y de escuela son parte determinante del recurso humano que representa esta exigente labor administrativa. Las competencias laborales genéricas y específicas que se deben poseer para ejercer estos puestos se materializan día a día en la gestión de cada carrera a su cargo. Por consiguiente, el debido cumplimiento de funciones para cada perfil en las 
distintas direcciones, así como, poseer las competencias necesarias, resultan dos aspectos que pueden enriquecer o deteriorar la ejecución de los objetivos institucionales trazados para el cumplimiento de las metas de cada carrera.

De esta forma, seleccionar adecuadamente el personal que se va a contratar para que ejerza la función de director de carrera o de escuela tiene que ser un proceso cuidadoso, y aún más que eso, debe ser un proceso que tenga en mente el tipo de competencias deseadas para cada puesto. Como resultado, una gestión de recurso humano que pueda contar con los instrumentos adecuados para seleccionar, evaluar y tomar decisiones respecto al cumplimiento de objetivos y al nivel de competencias con el cual lo realice, es una gestión organizada y eficiente, la misma que podrá tomar medidas basadas en lo observable y medible.

\section{OBJETIVOS DEL ESTUDIO}

\section{Objetivo general}

Dilucidar el perfil laboral idóneo para el puesto de director de carrera de la Universidad Católica de Costa Rica.

\section{Objetivos específicos}

- Determinar las funciones de los directores de carrera de la Universidad Católica de Costa Rica.

- Definir las competencias del puesto de director de carrera de la Universidad Católica de Costa Rica.

\section{REVISIÓN DE LA LITERATURA}

\section{Definición de competencias}

Para definir el término competencias, Alles (2005) se basa en la definición de Spencer y Spencer: "competencia es una característica subyacente en un individuo que está casualmente relacionada a un estándar de efectividad y/o a una performance superior en un trabajo o situación" (p. 26). Más adelante, la misma autora aclara que una "característica subyacente significa que la competencia es una parte profunda de la personalidad y puede predecir el comportamiento en una amplia variedad de situaciones y desafíos laborales". (Alles 2005, p. 26). Por consiguiente, las competencias son las habilidades que cada persona posee para desempeñarse o desarrollar una 
actividad, en este caso labores de un puesto específico. Levy-leboyer, citada en Alles (2005), explica que las competencias son comportamientos que algunas personas poseen y otras desarrollan, según la situación que se les presente ( $p$. 32). También enuncia que esos comportamientos son observables cuando cada persona aplica sus aptitudes, personalidad y conocimientos en las labores cotidianas. (Alles 2005, p. 32).

\section{Clasificación de competencias}

Alles (2005), propone la siguiente clasificación de Spencer y Spencer:

1. Competencias de logro y acción

- Orientación al logro

- Preocupación por el orden, calidad y precisión

- Iniciativa

- Búsqueda de información

2. Competencias de ayuda y servicio

- Entendimiento interpersonal

- Orientación al cliente

3. Competencias de influencia

- Influencia e impacto

- Construcción de relaciones

- Conciencia organizacional

4. Competencias gerenciales

- Desarrollo de personas

- Dirección de personas

- Trabajo en equipo y cooperación

- Liderazgo
5. Competencias cognoscitivas

- Pensamiento analítico

- Razonamiento conceptual

- Experiencia técnica/profesional/ de dirección

6. Competencias de eficacia personal

- Autocontrol

- Confianza en sí mismo

- Comportamiento ante los fracasos

- $\quad$ Flexibilidad (p. 31)

Estas competencias son genéricas, las más comunes y utilizadas con mayor frecuencia, por lo tanto aplicables a todos los puestos y sirven como punto de partida tanto para el diseño de perfiles como en calidad de diccionarios para las empresas. Alles (2005), menciona que "las competencias cardinales, generales o genéricas son aquellas que todos los integrantes del personal de una empresa deberán tener. Estas, a su vez, podrán transformarse en específicas cuando sean desglosadas en grados y conformen el perfil del puesto" (p. 92). Tales competencias son compromiso, ética, prudencia, justicia, fortaleza, orientación al cliente, orientación a los resultados, calidad del trabajo, sencillez, adaptabilidad al cambio, temple, perseverancia, integridad, iniciativa, innovación, flexibilidad, liderazgo, autocontrol, desarrollo de las personas y conciencia organizacional. 


\section{Tipos de competencias}

Según Müller (2011), las competencias se dividen en tres diferentes categorías:

\section{Básicas}

Las competencias básicas son las que se forman inicialmente durante los primeros años de nuestra educación, por ende, se aprenden tanto en la escuela como en el colegio. Estas, entonces, llegan a formar una piedra angular para desempeñarse de manera satisfactoria en un puesto de trabajo. Algunos ejemplos que se pueden enumerar son: la habilidad para leer, escribir y hablar; solucionar operaciones matemáticas; resolver problemas; conocimiento y manejo adecuado de las tecnologías de información (TICS), entre otros.

\section{Conductuales o genéricas}

Las competencias conductuales o genéricas son aquellas que explican actitudes de un mayor nivel; es decir, se consideran enfáticamente características o atributos personales, actitudes y comportamientos, más que estándares mínimos de desempeño de una tarea en particular. Para mencionar algunos de los ejemplos que se pueden categorizar como competencias conductuales o genéricas se pueden citar la orienta- ción al logro, comunicación efectiva, iniciativa, rigurosidad, flexibilidad, innovación y la negociación. Asimismo, Müller señala que bajo esta clasificación existe un subconjunto que son las competencias de "empleabilidad", llamadas así porque se refieren a las capacidades necesarias obligatoriamente para ingresar, mantenerse $y$ desarrollarse en el mundo del trabajo. Algunos ejemplos de estas competencias de empleabilidad serían el emprendimiento, el aprender a aprender y la efectividad personal.

\section{Funcionales}

Finalmente, se encuentran las competencias denominadas funcionales o también competencias técnicas. Son aquellas requeridas para desempeñar las actividades que componen una función laboral, según estándares de calidad establecidos por la empresa y/o por el sector productivo.
a. Específicas: están delimitadas a determinados puestos de trabajo u ocupaciones.

Algunos ejemplos de las competencias funcionales específicas serían: operar maquinaria especializada, confeccionar menú gastronómico, asesorar al cliente en proyectos de construcción.

b. Transversales: son aquellas rele- 
vantes a una gran cantidad de ocupaciones o funciones laborales dentro de un sector productivo, dentro de una familia de ocupaciones o incluso para todos los sectores productivos o empresas.

Algunos ejemplos de las competencias funcionales transversales serían: supervisar y controlar una obra, asegurar la calidad en faenas productivas, entre otros (p. 15-19).

\section{Gestión de talento por competencias}

En Selección de competencias de Martha Alles (2006), la escogencia del personal, sin importar cuál puesto sea dentro de la institución, no se encuentra delimitada por normas legales (p. 19). Las decisiones y prácticas correctas surgen al utilizar el medio adecuado y profesional para realizar las escogencias. De la misma manera, es de sentido común que se espera que la persona a contratar sea la mejor calificada para cada puesto. Y es aquí donde entra en juego la necesidad de prestarle atención a las competencias. Cuando se dice que se tiene que "seleccionar a la mejor persona para cada puesto" se debe dar la pauta para la contratación. Esto quiere decir que la idea no es seleccionar a la mejor persona posible o disponible, o que la organización pueda pagar, sino la mejor persona "en relación con el puesto a ocupar". (Alles, 2006, p. 19).
La misma autora explica que la metodología de Gestión de Recursos Humanos por competencias es un enfoque algo ambicioso, ya que este pretende que cada persona que ocupa una posición sea "adecuada y apta" para realizar un determinado trabajo o desempeñarse en un determinado puesto (Alles, 2006, p. 22). Así, la colocación de una persona en el puesto más adecuado respecto a sus capacidades está directamente relacionada con la motivación de la misma. De esta manera se puede observar que muchas organizaciones tratan de lograr una mejor articulación en lo que se relaciona a cada persona con su puesto, ya que si esta se logra adecuadamente, se puede llegar a una situación en donde tanto el empleador como el empleado se benefician y esto es tan bueno para la organización como para la persona que se desempeña en un puesto en específico, ya que aumenta su motivación. (Alles, 2006, p. 35).

Según Alles (2008), la administración de los recursos humanos es de gran importancia para todos los gerentes, independientemente de su área de trabajo y es por ello, que estos deben conocer las herramientas de recursos humanos para futuramente evitar:

- tomar la persona equivocada;

- $\quad$ tener un personal insatisfecho;

- falta de compromiso; 
- que sus empleados sientan que hay injusticias;

- que el personal no esté capacitado, o que estándolo en el momento de su incorporación, pierda luego su nivel (p. 19).

Bajo la concepción de este tipo de administración, tanto el departamento de Recursos Humanos de la Universidad Católica de Costa Rica como la Dirección General van a desempeñar funciones específicas en su cotidianeidad que se relacionan directamente con el reclutamiento, asesoramiento y evaluación del desempeño de los directores de carrera contratados para cada una de sus direcciones académicas. Por esta razón es necesario que desde el inicio de este ciclo de contratación de recurso humano se lleven los debidos procesos y se ejecuten de la manera más justa y beneficiosa para la institución.

Al ejecutar una gestión de recursos humanos por competencias, esta va a producir empleados comprometidos y competitivos, así como un área de recursos humanos completamente profesional —en la que no se puede improvisar-. Además, la contratación de los directores de carrera basada en las competencias laborales generales debe ser tomada como una prioridad dado a que, como lo menciona Cecilia Vélez (s.f.), Ministra de Educación Nacional de
Colombia, las nuevas organizaciones productivas sufren cambios radicales día a día, originados por la competitividad exigida en los mercados globales y en el rápido avance de la tecnología (p. 7). Igualmente, se precisa de relaciones personales basadas en redes y equipos de trabajo, que usen tecnologías y procesos flexibles y que tengan en cuenta a los clientes. Por consiguiente, los países latinoamericanos necesitan un recurso humano versátil y multifuncional, que identifique oportunidades para crear negocios, asociarse con otros o generar alianzas productivas. Personas que sean capaces de adaptarse a los cambios del entorno, de autodirigirse y autoevaluarse, de relacionarse apropiadamente con otros y de aprender cada vez más sobre su trabajo.

\section{Perfil por competencias}

Para definir las competencias de un puesto, deben primero elaborarse los manuales de puestos, los cuales contienen las funciones y labores que debe desempeñar el trabajador. Al respecto, Alles (2005) comenta que "a partir del perfil, el puesto a cubrir tendrá competencias derivadas del conocimiento y las aquí descritas (...) Una correcta selección deberá contemplar ambos tipos de requerimientos, ya que el conjunto conforma el perfil requeri- 
do" (p. 33). Müller (2011), también especifica que un modelo de gestión o selección por competencias ayuda a la organización a:

- Asegurar que sus empleados tengan las habilidades y conocimientos requeridos para desempeñarse satisfactoriamente en su puesto de trabajo.

- Alinear el día a día de sus empleados con el modelo de negocio y los comportamientos esperados.

- Facilitar que su personal sea responsable de su propio desempeño, progresos y desarrollo.

- Integrar los distintos sistemas y prácticas de gestión de personas bajo un enfoque coherente.

- Gestionar el talento, esto es, generar las condiciones y prácticas que permitan atraer, retener y desarrollar a las personas con el fin de lograr contribuciones superiores (p. 50).

Todo esto a su vez, entonces, produce sistemas de gestión de personas integradas entre sí, perfiles más claros y rigurosos, reclutamiento y selección más efectivos, capacitaciones más focalizadas, mejores ajustes entre los requerimientos del perfil de cargo y su ocupante, un personal más competente y personas más productivas y alineadas.

\section{Roles del administrador educativo}

Un centro educativo es una empresa, y como tal un administrador educativo tiene las mismas funciones que un administrador; ya que poseen características similares: gestionan recursos materiales, financieros y humanos, toman decisiones, supervisan a los docentes, representan a la institución, entre otras. Las funciones de la gerencia son planear, organizar, dirigir y controlar. Judge y Robbins (2009), describen que la función de planear abarca la definición de las metas de una organización, el establecimiento de la estrategia general para lograrlas y el desarrollo de un conjunto exhaustivo de planes para integrar y coordinar las actividades. Organizar incluye la determinación de cuáles tareas van a realizarse, quién las realizará, cómo, quién reportará a quién y dónde se tomarán las decisiones. Luego está dirigir y coordinar el trabajo. Y finalmente, controlar se logra mediante la vigilancia del desempeño de la organización (p. 6). Henry Mintzberg (citado en Judge y Robbins, 2009, p. 7), enuncia que el gerente desempeña 10 roles, los cuales se agrupan en interpersonales, informativos y toma de decisiones; estos se presentan en la Tabla 1. Según la situación, el gerente asumirá uno o varios de los roles descritos anteriormente, para dar solución a lo presentado según su experiencia. 
Tabla 1. Roles del gerente

\begin{tabular}{l|l}
\hline \multicolumn{1}{c|}{ Rol } & \multicolumn{1}{c}{ Definición } \\
\hline \multicolumn{2}{c}{ INTERPERSONAL } \\
\hline Representante & Figura simbólica \\
\hline Líder & Contrata, capacita, motiva y disciplina empleados \\
\hline Enlace & Contacto externo \\
\hline \multicolumn{2}{|c}{ INFORMATIVO } \\
\hline Vigilante & Recibe y obtiene información \\
\hline Difusor & Transmite la información obtenida \\
\hline Vocero & Representa la organización externamente \\
\hline
\end{tabular}

TOMA DEDECISIONES

\begin{tabular}{l|l}
\hline Empresario & Inicia y supervisa proyectos \\
\hline Manejador de dificultades & Toma acciones correctivas a problemas imprevistos \\
\hline Asignador de recursos & Asigna recursos humanos, físicos y monetarios \\
\hline Negociador & Analiza y negocia temas para lograr ventajas \\
\hline
\end{tabular}

Fuente: Judge y Robbins (2009) modificado por Elizondo y Román

\section{Competencias de un administrador} educativo

Venegas (2011), indica que para una gestión por competencias del administrador se deben tomar en cuenta los siguientes elementos:

- Saber adaptarse a los cambios y situaciones ambiguas

- Pensar estratégicamente

- Tomar decisiones correctas en situaciones de mucha presión

- Aprender y dominar nuevas tecnologías

- Administrar equipos de trabajo, delegar y ampliar oportunidades
- Favorecer un clima propicio: ampliar desafíos y oportunidades que favorezcan el desarrollo de equipos

- Orientado hacia equipos de trabajo

- Construir equipo de talentos mediante el desarrollo del potencial humano

- Fomentar buenas relaciones: negociación, colaboración, compartir

- Sensibilidad: interés por los demás y tomar decisiones al respecto

- Equilibrio: establecer prioridades en vida personal y profesional

- Autoconocimiento

- Liderazgo 
Igualmente, destaca las áreas de gestión y competencias:

- Gestión de liderazgo

- Gestión de trabajo en equipo

- Gestión en toma de decisiones

- Gestión curricular

- Gestión de calidad

- Gestión en resolución de conflictos
- Gestión de recursos físicos y financieros

- Gestión de recursos humanos

- Gestión política

- Otros componentes de gestión requeridos para el logro de los propósitos educativos en la administración de la educación.

\section{METODOLOGÍA}

\section{Tipo de estudio}

Por la naturaleza del trabajo esta investigación responde a un enfoque cualitativo ya que según Sampieri et al. (2010), este "se enfoca a comprender y profundizar los fenómenos, explorándolos desde la perspectiva de los participantes en un ambiente natural y en relación con el contexto" (p. 364). La investigación tuvo lugar en la Universidad Católica de Costa Rica, específicamente en la dirección académica, tomando en cuenta las experiencias de cada uno de los nueve directores, sobre sus labores cotidianas para elaborar su perfil del puesto. Por lo tanto, el diseño es narrativo: es decir, "el investigador recolecta datos sobre las historias de vida y experiencias de ciertas personas para describirlas y analizarlas" (Sampieri et al., 2010 p. 504). Como mencionan los autores anteriores "los estudios exploratorios se realizan cuando el objetivo es examinar un tema de investigación poco estudiado del cual se tienen muchas dudas (p. 100), y es una investigación descriptiva dado que esta busca especificar las propiedades, características y perfiles de personas que se sometan a un análisis. (Sampieri et al., 2010 p. 103).

\section{Población y muestra}

A enero del 2013, la institución cuenta con 130 empleados en su sede central, entre directores de carrera, asistentes académicos y administrativos, jefes de departamento, directores generales, profesores y rector. Sin embargo, en este proyecto de investigación solamente participarán los directores de carrera que poseen a su cargo los niveles de bachillerato y licenciatura, de cada uno de los programas que brinda la universidad, a saber: educación especial, ciencias teo- 
lógicas, psicología, educación preescolar, educación general básica, profesorados, administración de empresas, enseñanza del inglés, orientación educativa, estudios generales e ingeniería de sistemas. En total son 10 directores de carrera con las anteriores características, pero para la investigación participaron solamente nueve, ya que por situación médica el director de derecho no pudo ser entrevistado.

\section{Instrumentos}

Las entrevistas estructuradas aplicadas a los directores de carrera fueron construidas por los investigadores. Las mismas constan de tres páginas, en las cuales se les consulta datos como el grado académico que poseen, idiomas que hablan y nombre del puesto que actualmente desempeñan. La entrevista se compone de seis preguntas dentro de las cuales los directores definen sus labores, responsabilidades, requisitos del puesto; señalan algunas competencias y agregan qué les gustaría cambiar en su dirección (Apéndice 1).

\section{Metodología de recolección y análisis de datos}

Según Sampieri et al. (2010), "la recolección de datos ocurre en ambientes naturales y cotidianos de los participantes o unidades de análisis" (p. 409). Más adelante, definen que el principal instrumento en la recolección de datos es el investigador. Por lo tanto se realizó una entrevista al jefe de recursos humanos, para solicitarle información sobre el enfoque por competencias. En esta entrevista, el compañero recalcó que en la institución no se han elaborado los perfiles de los funcionarios.

Después de una exhaustiva revisión de datos sobre cómo elaborar perfiles de puestos se realiza una propuesta basándose en el diseño de Pastor (2005):

1. Datos personales: información personal del funcionario.

2. Puesto: nombre del puesto, dirección a la que pertenece.

3. Descripción del puesto: describir las principales labores del puesto.

4. Requisitos del puesto: son los requerimientos mínimos para optar por el puesto.

5. Responsabilidades: se definen las responsabilidades que debe tener sobre información confidencial, equipo y materiales a cargo.

6. Habilidades y destrezas.

7. Competencias: definición de las competencias del puesto (p. 41-42).

Para lo cual, se comienza a recolectar la información de las labores del puesto de los participantes, por medio de entrevistas, desglosando cada una de sus funciones (Apéndice 1). Para definir las competencias, la investigación 
se basó en Alles (2005), quien indica que añaden niveles según el grado en que cuando se establecen competencias, se deben ser cumplidas, tales como:

Tabla 2. Grados en los que se se deben cumplir las competencias

\begin{tabular}{l|l} 
A & Alto \\
\hline B & Bueno, por encima del estándar \\
\hline C & Mínimo necesario para el puesto \\
\hline D & Insatisfactorio
\end{tabular}

Fuente. Alles (2005). Elaboración propia.

\section{ANÁLISIS DE RESULTADOS}

Es importante destacar que todos los directores entrevistados poseen grado académico de maestría, a excepción de la actual directora de la carrera de educación especial, la cual posee el grado de doctorado en educación. Todos tienen a su cargo los niveles de bachillerato y licenciatura según su carrera a cargo, e indicaron que el puesto que ostentan es "director de carrera" y están bajo la dirección de la Dirección General Académica.

El primer objetivo de la investigación: determinar el perfil profesional del director de carrera de la Universidad Católica, según las entrevistas, recae en cinco áreas básicas:

1. Estudiantes: a. Atención en períodos de matrícula y seguimiento del plan de estudios: orientar al estudiante en cuanto a lo que debe matricular según los cursos de la oferta académica.

b. Levantar requisitos, lo cual aplica cuando un estudiante necesita cursar alguna materia cuyos requisitos no se cumplen en su totalidad.

c. Solicitud de cursos por suficiencias y tutorías: recibir, autorizar y asignar docentes según las solicitudes y plan de estudios de los estudiantes.

d. Atender la solicitud de estudio de convalidaciones internas y externas, dar seguimiento a la 
autorización de los cursos tanto de carrera como de los cursos de servicio que brindan las otras carreras.

e. Alguna atención especial o específica que requieran los alumnos; por vía telefónica, cartas o correos.

2. Docentes:

a. Atender las consultas de los docentes.

b. Entrevistar docentes que se requieran contratar, tratando de garantizar un proceso de selección de calidad.

c. Ser un guía, en la aplicación de los contenidos.

d. Supervisar a los docentes.

e. Velar porque mantengan las guías didácticas actualizadas.

f. Realizar una reunión con el personal docente, mínimo una vez al cuatrimestre, para revisar aspectos propios de la academia y la gestión de la Universidad.

3. Administrativo:

a. Atender requerimientos de los compañeros funcionarios.

b. Realizar la oferta cada cuatrimestre, según las necesidades de la carrera y enviarla a la dirección general académica, para su aprobación y publicación en el departamento de admisiones.

c. Tramitar pagos de los profesores.

d. Velar para que la bibliografía establecida por los docentes se encuentre en la biblioteca de la Universidad; caso contrario, realizar el trámite respectivo para la compra de los libros.

e. Responder las solicitudes de la Dirección General Académica, la Rectoría o sus representantes.

f. Asistir a reuniones.

g. Elaborar informes

4. Curricular:

a. Revisión y actualización de los planes de estudio.

b. Revisión y actualización de guías didácticas.

c. Gestiones de la carrera ante CONESUP.

5. Investigativo:

a. Nombrar y autorizar directores y lectores para trabajos finales de graduación.

b. Representar a la dirección académica en las defensas de trabajos finales de graduación.

c. Dar seguimiento a los trabajos finales de graduación, asegurando 


\author{
el acompañamiento del director \\ y lector, en forma apropiada.
}

Las anteriores labores, se realizan tanto para los estudiantes de la sede central, como de las sedes en las que se imparten las carreras a cargo.

También se procedió a realizar un análisis de lo indicado en el Estatuto Orgánico sobre las funciones de los directores de carrera con lo obtenido en las entrevistas.

Tabla 3. Comparación de las funciones del Estatuto Orgánico con las funciones realizadas por los directores de carrera

\begin{tabular}{|c|c|}
\hline Estatuto Orgánico & $\begin{array}{c}\text { Función según entrevista, que coincide con el } \\
\text { Estatuto Orgánico }\end{array}$ \\
\hline $\begin{array}{l}\text { Actuar como superior jerárquico inmediato del personal } \\
\text { docente de las carreras adscritas a su Escuela. }\end{array}$ & $\begin{array}{l}\text { Reunir a docentes al menos una vez al cuatrimestre para revisar } \\
\text { aspectos propios de la academia y de la gestión administrativa } \\
\text { de la Universidad. }\end{array}$ \\
\hline \multicolumn{2}{|l|}{$\begin{array}{l}\text { Velar por el cumplimiento de la misión, visión, naturaleza y } \\
\text { los fines de la Universidad Católica de Costa Rica. }\end{array}$} \\
\hline \multicolumn{2}{|l|}{ Promover el logro de los objetivos de la Institución. } \\
\hline \multicolumn{2}{|l|}{$\begin{array}{l}\text { Ejecutar las disposiciones que emanen de las autoridades y } \\
\text { de entes colegiados con poder de decisión de la Universidad } \\
\text { Católica de Costa Rica. }\end{array}$} \\
\hline $\begin{array}{l}\text { Cooperar con el Director General Académico y el Decano en } \\
\text { las gestiones interdisciplinarias que estos tienen a su cargo. }\end{array}$ & $\begin{array}{l}\text { Atender a las reuniones de Consejo Académico una vez al mes. } \\
\text { Preparar y presentar informes requeridos por la Dirección } \\
\text { General Académica. } \\
\text { Analizar y realizar las modificaciones pertinentes a los planes } \\
\text { de estudio a cargo y presentarlas a la Dirección General Acadé- } \\
\text { mica para su revisión y trámite. }\end{array}$ \\
\hline $\begin{array}{l}\text { Mantener estrecha relación con los coordinadores de las } \\
\text { Subsedes donde se desarrollan las carreras a su cargo. }\end{array}$ & $\begin{array}{l}\text { Visitar las Sedes Regionales para atender las solicitudes de los } \\
\text { estudiantes y los docentes. } \\
\text { Coordinar las capacitaciones del personal docente de la Sede } \\
\text { Central y Sedes Regionales. }\end{array}$ \\
\hline \multicolumn{2}{|l|}{ Nombrar comisiones para el estudio de temas específicos. } \\
\hline $\begin{array}{l}\text { Proponer ante el Director General Administrativo el nom- } \\
\text { bramiento de los empleados administrativos que la Escuela } \\
\text { requiera. }\end{array}$ & $\begin{array}{l}\text { Seleccionar los currículos y entrevistar a los nuevos docentes } \\
\text { aspirantes. }\end{array}$ \\
\hline \multicolumn{2}{|l|}{$\begin{array}{l}\text { Dar cuenta a los órganos universitarios competentes de las } \\
\text { irregularidades cometidas por los funcionarios de la Escuela, } \\
\text { para lo que corresponda. }\end{array}$} \\
\hline $\begin{array}{l}\text { Mantener control permanente del cumplimiento de políticas, } \\
\text { normas, programas y acuerdos institucionales. }\end{array}$ & \\
\hline
\end{tabular}




\begin{tabular}{|c|c|}
\hline $\begin{array}{l}\text { Velar por el funcionamiento y mejoramiento de las carreras, } \\
\text { el adecuado desarrollo de los cursos y el mantenimiento de } \\
\text { todos los equipos, en coordinación con los responsables de } \\
\text { cada área. }\end{array}$ & \\
\hline \multicolumn{2}{|l|}{ Formar parte y presidir el Consejo de Escuela. } \\
\hline $\begin{array}{l}\text { Servir de enlace entre los profesores de las carreras y las } \\
\text { diferentes dependencias administrativas de la universidad. }\end{array}$ & $\begin{array}{l}\text { Orientar a los docentes a cargo en cuestiones académicas, } \\
\text { administrativas y operativas de la universidad. }\end{array}$ \\
\hline $\begin{array}{l}\text { Elaborar el Plan anual y el anteproyecto de presupuesto, } \\
\text { correspondiente a la escuela, dentro del período de tiempo } \\
\text { establecido por la dirección administrativa. }\end{array}$ & $\begin{array}{l}\text { Estructurar, ejecutar y dar seguimiento al PAO. } \\
\text { Planificar y presentar el presupuesto de los recursos necesarios } \\
\text { para el desarrollo de la carrera una vez al año a la Dirección } \\
\text { General Administrativa. }\end{array}$ \\
\hline $\begin{array}{l}\text { Presentar al Director General Académico y al Decano el } \\
\text { cuadro de profesores, para su aprobación. }\end{array}$ & $\begin{array}{l}\text { Elaborar la oferta académica. } \\
\text { Autorizar y realizar los cambios de horario y cambios de } \\
\text { profesores en el período establecido. }\end{array}$ \\
\hline $\begin{array}{l}\text { Firmar títulos, certificados y diplomas debidamente auto- } \\
\text { rizados. }\end{array}$ & $\begin{array}{l}\text { Revisar, firmar y sellar los programas que solicitan los estudian- } \\
\text { tes para convalidaciones con otras universidades. }\end{array}$ \\
\hline Presentar cada año el Plan de Trabajo y el Informe de Labores. & Realizar el informe de Autoevaluación. \\
\hline \multicolumn{2}{|l|}{$\begin{array}{l}\text { Cumplir con otras disposiciones que el presente estatuto, el } \\
\text { Rector y el Director General Académico le señalen. }\end{array}$} \\
\hline & $\begin{array}{l}\text { Atender al público: estudiantes, docentes, administrativos y } \\
\text { público en general. }\end{array}$ \\
\hline & $\begin{array}{l}\text { Revisar y responder las solicitudes y comunicados que ingresan } \\
\text { por medio de los correos electrónicos de la carrera. }\end{array}$ \\
\hline & Promocionar la carrera para atraer nuevos estudiantes. \\
\hline & $\begin{array}{l}\text { Gestionar que los docentes actualicen la bibliografía en las } \\
\text { guías didácticas. }\end{array}$ \\
\hline & $\begin{array}{l}\text { Levantar requisitos de matrícula, en los casos que el estudiante } \\
\text { necesite cursar alguna materia cuyos requisitos no se cumplan } \\
\text { en su totalidad. }\end{array}$ \\
\hline & $\begin{array}{l}\text { Analizar la evaluación docente y brindar la realimentación } \\
\text { correspondiente. }\end{array}$ \\
\hline & $\begin{array}{l}\text { Dar seguimiento y apoyo a los docentes durante el período } \\
\text { académico. }\end{array}$ \\
\hline & Hacer visitas a las aulas para dar seguimiento a los cursos. \\
\hline & $\begin{array}{l}\text { Tramitar los documentos para la convalidación interna y } \\
\text { equiparación externa, con su debido seguimiento. }\end{array}$ \\
\hline
\end{tabular}




\begin{tabular}{l|l}
\hline & $\begin{array}{l}\text { Atender las solicitudes de emisión de reportes e información } \\
\text { de Administración y Mercadeo, Departamento de Personal, } \\
\text { Dirección Administrativa, Dirección General Académica, } \\
\text { Departamento de Investigación, Departamento de Registro, } \\
\text { Dirección General de Vida Estudiantil y Extensión, Departamen- } \\
\text { to Financiero y Rectoría. }\end{array}$ \\
\hline & $\begin{array}{l}\text { Velar por el debido proceso de los trabajos finales de gradua- } \\
\text { ción: conocer, revisar y leer los trabajos finales de graduación, } \\
\text { así como asistir a sus respectivas defensas, asegurando el } \\
\text { acompañamiento del director y el lector, en forma apropiada. }\end{array}$ \\
\hline & $\begin{array}{l}\text { Hacer propuestas de capacitaciones, seminarios y demás } \\
\text { ventas de servicio y coordinar con SUFORPE el desarrollo de } \\
\text { las mismas. }\end{array}$ \\
\hline & $\begin{array}{l}\text { Hacer los debidos trámites y procesos estudiantiles, docentes y } \\
\text { curriculares para el CONESUP. }\end{array}$ \\
\hline & \begin{tabular}{l} 
Asistir a capacitaciones. \\
\hline
\end{tabular} \\
$\begin{array}{l}\text { Crear vínculos con personas o instituciones para establecer } \\
\text { posibles convenios con las carreras a cargo y la universidad. }\end{array}$ \\
\hline & $\begin{array}{l}\text { Coordinar con los docentes a su cargo la preparación de los } \\
\text { cursos virtuales de la carrera. }\end{array}$ \\
\hline $\begin{array}{l}\text { Revisión de los cursos virtuales en coordinación con el encar- } \\
\text { gado del proyecto. }\end{array}$ \\
\hline
\end{tabular}

Según se puede observar en el análisis anterior, la mayoría de funciones especificadas en el Estatuto Orgánico de la Universidad Católica no fueron mencionadas como funciones primordiales por los entrevistados. Interesantemente, la mayoría de funciones señaladas como indispensables que alegan tener los directores de carrera tampoco corresponden totalmente a lo que dispone el estatuto.

Para ejemplificar, una de las funciones primordiales que declara el estatuto es completamente diferente a lo que los entrevistados evidenciaron: "Promover el logro de los objetivos de la Institución". En sus labores cotidianas, inicialmente, para los directores de carrera, las metas y objetivos de la universidad no representan la tarea a cumplir, sino el atender lo urgente e inmediato. Los entrevistados declararon que ellos no tienen tiempo para desarrollar actividades que promuevan los objetivos de la universidad, el mejoramiento de la carrera o el atender las necesidades académicas de sus unidades respectivas, ya que el trabajo administrativo de oficinista es el que les consume prácticamente todo el tiempo. De esta manera, se concluye que la función "Promover el logro de los 
objetivos de la Institución" se está cumpliendo, pero tal vez no con el énfasis que esta requiere.

El $100 \%$ de los entrevistados listaron esta función (gestionar trámites administrativos) como la más destacada debido a la cantidad de tiempo que consume. De hecho, dos de ellos especificaron claramente que la cantidad de trabajo es tal que ellos prefieren llevar gran parte del trabajo administrativo de oficina a la casa, ya que ahí pueden concentrarse mejor y terminar sus labores sin tener la presión de realizar las funciones académicas junto con las administrativas. Adicionalmente, muchos de ellos recalcaron que cuando no hay estudiantes, docentes, compañeros de trabajo o cualquier particular por atender siempre va a haber trabajo acumulado por los medios electrónicos, ya sean llamadas, mensajes y correos electrónicos que se deben responder con la mayor brevedad posible.

Como otra observación, en el Estatuto no se encuentra detallada la función de atraer nuevos estudiantes a la carrera; sin embargo, los directores de carrera aseguran que esta es una función primordial, y que el número de estudiantes matriculados en sus carreras significa un vínculo directo con la labor que ellos hacen tanto para mantener a los estudiantes activos como para atraer a los de nuevo ingreso. Más cuantitativamente hablando, tres de los directores entrevistados expresaron que esta función resulta sumamente desgastante, ya que demanda procesos y actividades continuas, las cuales requieren de perseverancia y seguimiento. Ellos mismos proponen que esta función sea delegada a otras instancias dentro de la Universidad Católica que se especializan en atracción de estudiantes, para ellos poder ejercer su rol de director de carrera propiamente.

Finalmente, se pudo confirmar en las entrevistas que la mayoría de los directores de carrera no se encuentran contratados a tiempo completo. En su gran parte, ellos están contratados un medio tiempo, lo cual equivale aproximadamente a 20 horas semanales. Cuando se les preguntó sobre las funciones más importantes, ellos respondieron muy claramente sobre lo que "se suponía que se debía hacer" en cada una de sus direcciones; no obstante, algunos evidenciaron que muchas de esas funciones que ellos debían hacer no las podían ejecutar en su nivel óptimo por motivos de tiempo. Además, algunos de ellos sacaron a relucir que ellos no contaban con el tiempo - la energía necesarios para ejecutar tantas funciones dado a que cuentan con otras responsabilidades en otras instituciones o proyectos personales fuera de la Universidad Católica.

Adicionalmente, algunos parecieron un poco inseguros a la hora de 
contestar y utilizaron expresiones tales como: "No sé si esto me toca hacerlo, pero....", o"Yo siento que eso es parte del trabajo". Para ejemplificar, un director de carrera testificó, cuando se le preguntó por sus funciones, que él/ella no estaba completamente seguro si algunas funciones que realizaba estaban dentro de sus responsabilidades. Igualmente, este director afirmó que se suponía que tenía que realizar algunas funciones como la de velar por una bibliografía adecuada en la biblioteca; empero, este no lo hacía porque no tenía el tiempo para pensar en ese tipo de actualizaciones.

Estas situaciones apoyan la conclusión que otro de los entrevistados puntualizó: cada director de escuela percibe su trabajo de una manera diferente. Este director muy respetuosamente explica que cada director entiende su papel dentro de su dirección a su conveniencia, ya que él asegura que no hay directrices que especifiquen qué hacer y qué no hacer dentro de sus gestiones. Esto produce, entonces, que cada director priorice las funciones en un diferente orden y eso causa vacíos de comunicación de escuela a escuela.

En cuanto a los requisitos que deben poseer los directores para asumir este puesto, indicaron los siguientes:

1. Poseer conocimientos técnicos de la carrera.
2. Tener experiencia docente, al menos cinco años.

3. Poseer grado académico igual o mayor a los programas que se imparten en la carrera. Igualmente, algunos recomendaron poseer la maestría o conocimientos en administración educativa.

4. Solo los directores de las carreras de inglés e ingeniería de sistemas, indicaron que es importante el manejo del idioma inglés como segunda lengua.

En cuanto a responsabilidades, comentan que el director debe ser una persona discreta, prudente y es el ente responsable de cumplir y hacer cumplir las labores anteriormente descritas.

El segundo objetivo de la investigación era definir las competencias del puesto de director de carrera. De las competencias presentadas en el instrumento, los directores comentan que todas las competencias son necesarias, solamente uno comentó que "tomar decisiones bajo presión" no la recomienda porque en momentos en donde embarga la emoción no es recomendable tomar alguna decisión ya que se debe tomar un tiempo de reflexión, lo que sí indica que debe ser una competencia es "trabajar bajo presión".

La capacidad investigativa, de abstracción, análisis y síntesis se ven reflejadas en los informes que deben 
presentar a los superiores. Asimismo, varios directores enfatizaron que quien tenga este puesto debe de ser alguien con altas competencias investigativas e interpersonales a la vez, dado a que es una dirección en donde los estudiantes se acercan para dialogar y cuestionar lo que aprenden en clases. Ellos especifican que es urgente tener interés por la vida universitaria y tener apertura para ese diálogo. Enfatizan en el liderazgo motivador que deben poseer y creen que es importante ser jefe y líder; tomando en cuenta que jefe es una figura que emana directrices y líder es la figura que apoya, motiva, supervisa. Además es importante el trabajo en equipo, tanto con el personal administrativo a cargo, como con el docente. También comentan sobre la buena ortografía que debe poseer un profesional y la expresión oral ya que deben dirigirse a futuros profesionales y tratar con compañeros colegas. La mayoría indica que para optar por este tipo de puestos no es necesario poseer un segundo idioma. Es vital la capacidad para establecer relaciones interpersonales adecuadas y propiciar un clima organizacional adecuado para la identificación, el diálogo y la búsqueda de soluciones a los conflictos; para los cuales se debe poseer iniciativa y ser creativo.

Según lo observado en las entrevistas, los actuales directores de carrera no fueron contratados bajo un perfil de puestos basado en competencias; por ende, se evidencian casos de fatiga, inconformidad, incertidumbre y hasta molestia con el puesto a desempeñar, al escuchar a algunos directores de carrera decir"yo no sé si trabajo para vivir o si vivo para trabajar","se supone que esas son mis funciones y competencias, pero la verdad tengo mucha dificultad lidiando con los profesores", "si uno no es seguro de sí mismo, uno aquí no sobrevive", "muchos somos académicos, no administradores. Así que ocupamos capacitación en términos de planificación estratégica. La administración la hemos tomado con los años" y "deberíamos de saber de manejo de recursos físicos y financieros pero la verdad es que no". Estas frases sugieren que un proceso de contratación por competencias pudo haber evitado la contratación de candidatos sin conocimiento de manejo de recursos o de personal docente, por mencionar algunos ejemplos. 


\section{CONCLUSIONES}

A la luz de los resultados obtenidos en las entrevistas y en la documentación revisada, se concluye que,

- Administrativamente, la Universidad Católica no cuenta con un manual de puestos, ni para los directores de carrera ni para los demás funcionarios de la institución, lo cual dificulta la gestión, ya que algunos directores desconocen si las labores que realizan corresponden estrictamente a sus funciones.

- A los directores de carrera se les dificulta cumplir con todas las funciones que se especifican en el Estatuto Orgánico de la universidad por múltiples razones: falta de tiempo, exceso de labores administrativas, y falta de recurso humano.

- Dado a que no existe un proceso de contratación basado en competencias, el $45 \%$ de los directores de carrera sienten que no tienen las habilidades necesarias para lidiar con algunos elementos del entorno en el que trabajan o con las tareas que deben desarrollar.

- La propuesta de un perfil por competencias para las direcciones de carrera es un proyecto que se puede generar desde el departamento de recursos humanos, en donde este departamento participe de una forma activa y en conjunto con los directores de carrera.

- Los directores de carrera, según lo establecido en el Estatuto Orgánico, cumplen con dos funciones, director de carrera y de escuela; los entrevistados indicaron que son directores de carrera, pero revisando el artículo 62 de dicho documento se indica que :

Las escuelas son unidades académicas, encargadas de una o varias carreras, que desarrollan la docencia, las actividades de investigación y la coordinación de lo relacionado con el Trabajo Social y Pastoral. Además, son las encargadas del desarrollo de los Planes de Estudio en las respectivas carreras.

Por lo tanto se propone que la nomenclatura correcta sea, por ejemplo: Director de carrera, Escuela de Administración de Empresas y así fusionar las funciones de un director de carrera y de escuela. 


\section{RECOMENDACIONES}

Es recomendable que la oficina de la dirección académica se encuentre cerca de las oficinas de los directores para que ejerza una mejor supervisión.

Se sugiere que los documentos como el plan estratégico y el DAFO estén al alcance de los miembros de la Institución, ya que los objetivos y metas de la institución se encuentran en dicho documento.

Es importante que el departamento de recursos humanos inicie el proceso de elaboración de perfiles de los puestos, que los mismos sean personalizados, no genéricos, y se actualicen según las necesidades de la institución.

Se recomienda revalorar la figura del director en el Estatuto Orgánico y fusionar las ya establecidas para director de carrera y escuela.

Es favorable que todos los directores de carrera, estén nombrados a tiempo completo e impartan uno o dos cursos para que compartan con los estudiantes y puedan realizar proyectos de su área en la Universidad.

Se recomienda que se brinde apoyo en la forma de recurso humano para la figura del director de carrera.

Para futuras investigaciones podría resultar enriquecedor entrevistar tanto a los asistentes de los directores de carrera como a quién esté encargado de la Dirección General Académica, para así obtener más fuentes de análisis y comparación.

Finalmente, se recomienda a las diferentes instituciones de educación superior, ya sean públicas o privadas, implementar un estudio similar a este, en donde se pueda comparar tangiblemente el tipo de director de carrera con el que se desea contar en la institución con el tipo de director de carrera que actualmente funge en este cargo. A su vez, estas investigaciones mostrarían, como consecuencia, el método de contratación, supervisión y evaluación del desempeño de dichos funcionarios. 


\section{REFERENCIAS}

Alles, Martha. (2008). Dirección estratégica de recursos humanos: Gestión por competencias. Granica: Buenos Aires.

Alles, Martha. (2006). Selección por competencias. Granica: Buenos Aires.

Alles, Martha. (2005). Diccionario de comportamientos: Gestión por competencias. Granica: Buenos Aires.

Estatuto orgánico de la Universidad Católica de Costa Rica, febrero 2011.

Judge, T. A., y Robbins, S. P. (2009). Organizational Behavior. London: Pearson.

Müller, Guillermo. (2011). Módulo 20: Gestión de Recursos Humanos: Modelo de Gestión por Competencias. Presentación de Power Point presentada en la Pontificia Universidad Católica de Chile, Chile. Recupe- rada de http://www.slideshare. net/lvive/modelo-gesti-nporcompetencias

Pastor, R. (2005) Cuestionario de Análisis de Puestos: Módulo de Procesos Laborales, Universidad de Costa Rica, Manuscrito no publicado.

Sampieri, R. H., Collado, C. F., \& Lucio, P. B. (2010). Metodología de la investigación. México: McGraw-Hill.

Vélez, Cecilia. (s.f.). Articulación de la Educación con el Mundo Productivo: Competencias Laborales Generales. Recuperado de: http://www. mineducacion.gov.co/1621/articles-106706_archivo_pdf.pdf

Venegas J., P. (2011). La educación en un contexto de calidad: enfoques siglo XXI. Lección Inaugural Curso Lectivo 2011. Dirección Regional de Turrialba. Cartago, Costa Rica. 


\section{APÉNDICE}

\section{Entrevista a los directores de carrera}

Nombre del puesto:

Grado Académico:

1. ¿Cuáles son las labores que realiza?

2. ¿Cuáles serían los requisitos para concursar por este puesto?

¿Cuáles responsabilidades demanda este puesto?

3. De las siguientes competencias, cuáles cree usted que son necesarias para su puesto y si es necesaria, especifique en qué grado.

\begin{tabular}{|l|l|}
\hline A & Alto \\
\hline B & Bueno, por encima del estándar \\
\hline C & Mínimo necesario para el puesto \\
\hline D & Insatisfactorio \\
\hline
\end{tabular}

\begin{tabular}{|c|c|c|c|c|c|c|}
\hline \multirow{2}{*}{ Competencia } & \multirow{2}{*}{$\begin{array}{c}\text { Sí es } \\
\text { necesaria }\end{array}$} & \multirow{2}{*}{$\begin{array}{c}\text { No es } \\
\text { necesaria }\end{array}$} & \multicolumn{4}{|c|}{ Grado } \\
\hline & & & A & B & $\mathrm{C}$ & D \\
\hline Capacidad de abstracción, análisis y síntesis & & & & & & \\
\hline Confiar en sí mismo & & & & & & \\
\hline Saber adaptarse al cambio & & & & & & \\
\hline Capacidad para organizar y planificar el tiempo & & & & & & \\
\hline Tomar decisiones bajo presión & & & & & & \\
\hline Ser flexible & & & & & & \\
\hline $\begin{array}{l}\text { Conocimientos sobre el área de estudio y la profesión, además } \\
\text { poseer la capacidad de aplicarlos en la práctica }\end{array}$ & & & & & & \\
\hline Aprender y dominar nuevas tecnologías & & & & & & \\
\hline Capacidad de comunicación oral y escrita & & & & & & \\
\hline
\end{tabular}




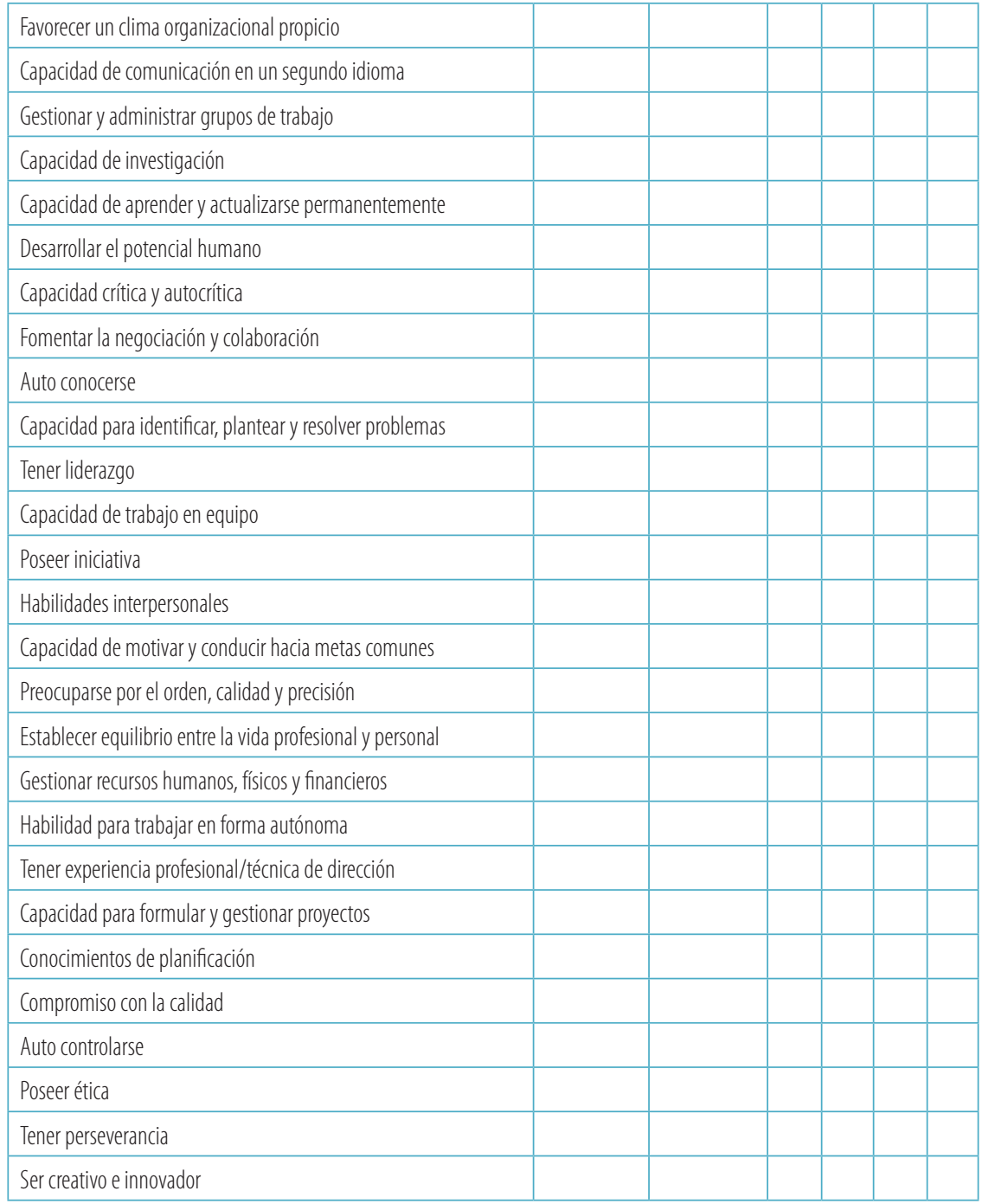

4. Para realizar su trabajo diario, ¿qué otras competencias cree que son necesarias?

5. ¿Qué cambios deberían darse en su unidad de trabajo para favorecer su gestión? 